\title{
Wound Healing Effects of Bentonite: A Rabbit Model Experimental Study
}

\author{
Qamar Zaman Phull*1, Ashique Ali Arain², Mashkoor Ahmed Ansari ${ }^{3}$ and Abdul Rahim Memon ${ }^{4}$ \\ ${ }^{1}$ Department of Pharmacology, Bilawal Medical College Jamshoro, Pakistan \\ ${ }^{2}$ Department of Pharmacology, Isra University, Pakistan \\ ${ }^{3}$ Department of Pharmacology, Bhittai Dental College, Pakistan \\ ${ }^{4}$ Department of Pharmacology, Isra University, Pakistan
}

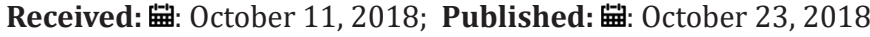

*Corresponding author: Qamar Zaman Phull, Department of Pharmacology, Bilawal Medical College Jamshoro, Pakistan

Ashique Ali Arain, Department of Pharmacology, Isra University, Pakistan

\section{Abstract}

Background: Injuries and infection result into wounds with variety of complexed stepwise sequenced events leading to either healing or complications. Wound management is based on multidimensional approach from removing the causative source, maintaining local antiseptic environment, preventing aggravating factors and encouraging the wound healing promoting agents. The best is the combination of all properties together bentonite was evaluated for such role in the current study. Study Design and Place: This Quasi Experimental work on Rabbit model took place at Isra University in department of Pharmacology/Pathology and Animal House.

Methodology: Wound was induced artificially in rabbits under anti septic protocols following their selection under inclusion/exclusion criteria. Bentonite was applied on the wound in the form of paste and followed up for observing improvement or complications. Wound size was measured on regular bases with tape while histological parameters were observed by the pathologists after periodical sacrifice of animals to document changes with time space.

Statistical Analysis: Mean size of wound was compared at different stages after induction like after 3days, after 7 days and after 13 days using ANOVA on SPSS version 22 while histological results were marked as,,,+++++++++ for mild, moderate, intense and severe to show various stages of healing.

Results: There was a significant difference in wound size between the initial sizes and the wound size at $7^{\text {th }}$ and $13^{\text {th }}$ days $3.98 \pm 0.49,3.18 \pm 0.62$ and $1.01 \pm 0.01$ respectively with p-value 0.0007 that was statistically highly significant supported by histological examination.

Conclusion: Bentonite possesses anti-inflammatory and wound healing properties.

\section{Introduction}

Wounds are observed as common presentation of either minor or major injuries and their healing (a biological phenomenon) is the ultimate goal. It gets affected by a variety of factors like diabetes, old age, vascular compromise and smoking etc. converting the wound into a chronic one which draws world's estimated $4 \%$ budgets for healthcare [1]. United States consumes an estimated $\$ 50$ billion annually with an average of $\$ 3.00-\$ 10,000.00$ per wound [2]. The healing mechanism consists four phases supposed to occur in sequence of timeframe with appropriate duration and intensity for ideal wound healing these are a) Hemostasis (Platelet activation followed by release of substances initiating the coagulation process).

b) Inflammation (mediated by substances like prostaglandin, complement proteins and cytokines released at injured site responsible for chemotaxis of inflammatory cells including neutrophils followed by macrophages resulting into apoptosis and phagocytosis within 1-2 days following injury propelling the wound into next phase).

c) Proliferation (Activated macrophages liberate PDGF, TGF, EDF, FGF, and VEGF responsible for angiogenesis followed by 
accumulation of fibroblasts and macrophages resulting into the formation of granulation tissue consequent conversion of fibroblast into myofibroblast).

d) Remodeling (characteristics include apoptosis of endothelial cells, myofibroblasts, and macrophages leaving behind the extracellular matrix proteins while remaining fibroblasts and the macrophages get replaced by collagen and it lasts for 6-24 months) [3].

A wound may heal with any of the three types of the healing namely primary intention, secondary intention and tertiary intention.

a) A wound Heals through primary intention when its edges are in close proximity to each other the best example is a surgical wound closed by staple or sutures characterized by minimal granulation tissue and scar.

b) Ulcers heal by secondary intension where wound edges have a clear gap in between to be filled by granulation tissue taking a longer time.

c) Tertiary intention wound healing is observed in infected wounds where there is a need of topical antimicrobial therapy over days that results into two granulation surfaces to be approximated later on with deeper, wider and prominent scar [4].

Healing is affected by certain systemic factors like age, gender, sex hormones, stress, diabetes, medication, alcoholism, smoking and nutrition as well as some local factors which include oxygenation, infection, foreign body, venous sufficiency, edema and raised local pressure like compartmental syndrome [5]. Such factors put the wound at risk of complications like keloid formation (excessive collagen production), hypertrophic scar (granulation tissue over produced), wound dehiscence (physical rupture) and wound contractures [6]. We explored the anti-inflammatory and wound healing potential of bentonite which contains montmorillonite as its principle constituent along with kaolinite, illite, and nonargillaceous detrital minerals [7]. Clay minerals possess natural properties against organic and inorganic contamination that can be enhanced by their further modification [8].

The history of using clay by humans to achieve and maintain health is as old as (Aristotle 384-322 BC). People also used to eat clay (geophagy) for infections, GI inflammation and topical use of mud spas (pelotherapy) to adsorb skin toxins along with treating rheumatism [9]. The geophagy may be attributed to cultural and religious practices or psychological and nutritional disorders but medical practitioners consider it as an abnormal behavior termed as pica syndrome. Some researchers consider it as a process of adaptation in mammals and primates or a physiological response to iron and zinc deficiency [9]. The current study was planned to evaluate the wound healing effects of bentonite in rabbit model.

\section{Methodology}

Study was approved by ERC (Ethical review committee) Isra University. Rabbits were purchased from Hyderabad city under inclusion criteria (weight 1-3kg, Healthy Rabbits of both genders) and exclusion criteria (underweight sick and pregnant rabbits). After acclimatization rabbits were given $4 \mathrm{~cm}$ longer cutaneous cut under aseptic surgical measures. Dressing was done with bentonite paste (purchased from local market and mixed with normal saline) on alternate days to observe the wound healing effects of bentonite. Wound size was measured with measuring tape while wound tissue placed in $10 \%$ formarlin jars for histology slides preparation. The histological grading was done using H\&E staining under light microscope by the pathologist of pathology department of the Isra University.

\section{Results}

Significant reduction in wound size was seen from the initial sizes $(4.0 \pm 0.00 \mathrm{Cm})$ to $(3.98 \pm 0.47)$ after 3 days while the size at $7^{\text {th }}(3.18 \pm 0.62 \mathrm{Cm})$ and $13^{\text {th }}$ days $(1.01 \pm 0.01 \mathrm{Cm})$ with statistically significance level of p-value 0.00007 . Histological features showed reduced inflammatory reaction from ++++ to ++ and + over week 1 and week 2 respectively. Fibroblast increased after $1^{\text {st }}$ week and reduced at the end of $2^{\text {nd }}$ week +++ to ++ while collagen contents increased after $2^{\text {nd }}$ week in comparison to $1^{\text {st }}$ week from ++ to +++ respectively showing wound healing (Tables $1 \& 2$ ) and (Figures 1-4).

Table 1: Wound size at various stages of study.

\begin{tabular}{|c|c|c|c|c|}
\hline Days & Mean Wound Size & SD & F-Value & P-Value \\
\cline { 1 - 3 } $3^{\text {rd }}$ & 3.98 & 0.47 & \multirow{2}{*}{113.43} & \multirow{2}{*}{0.00007} \\
\cline { 1 - 3 } $7^{\text {th }}$ & 3.18 & 0.62 & & \\
\cline { 1 - 3 } $14^{\text {th }}$ & 1.01 & 0.47 & & \\
\hline
\end{tabular}

Table 2: Histological features of the wound at various stages of study.

\begin{tabular}{|c|c|c|c|}
\hline Parameters & Day 3 & Day 7 & Day 14 \\
\hline Inflammatory Reaction & ++++ & ++ & + \\
\hline Angiogenesis & + & ++ & + \\
\hline Fibroblast & - & +++ & + \\
\hline Collagen Deposition & - & ++ & +++ \\
\hline
\end{tabular}

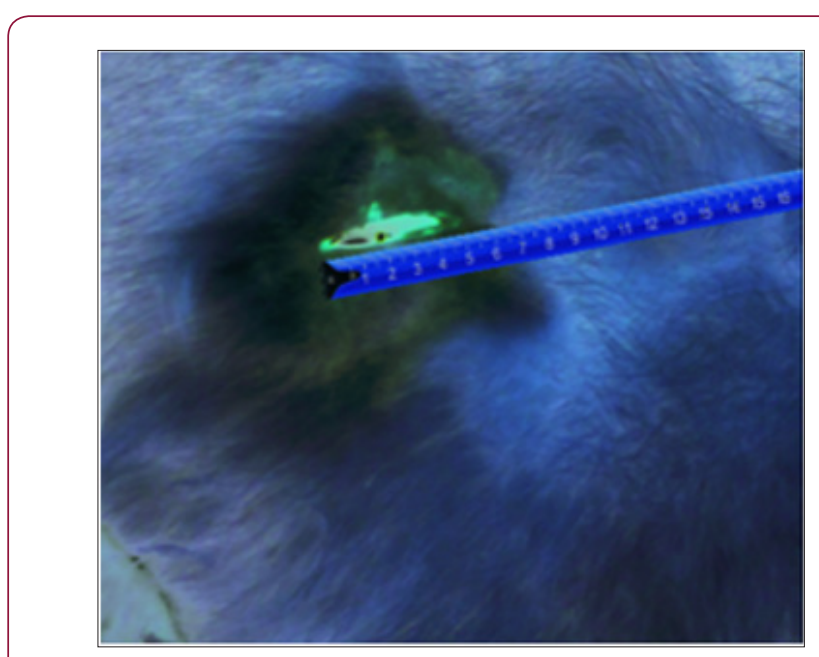

Figure 1: Wound at day 0 . 


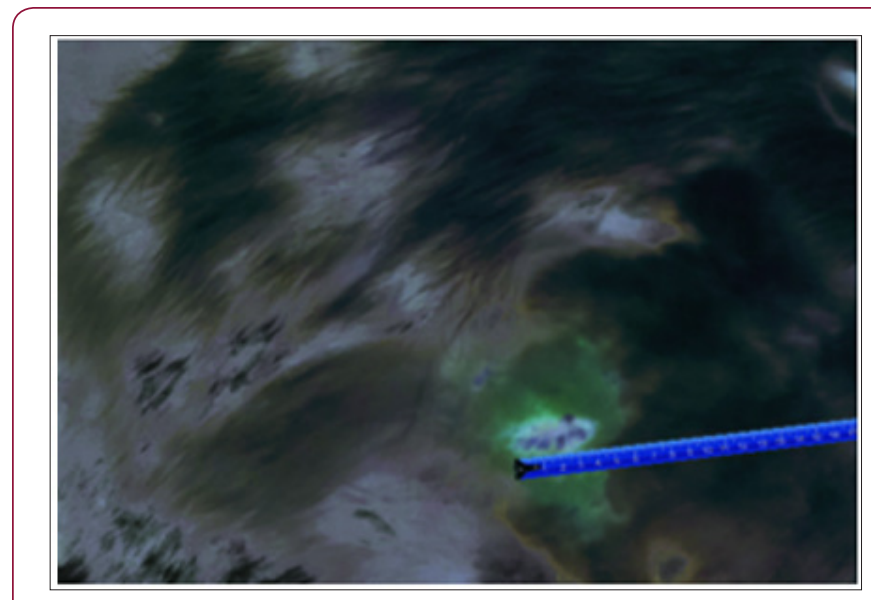

Figure 2: Wound at day 3.

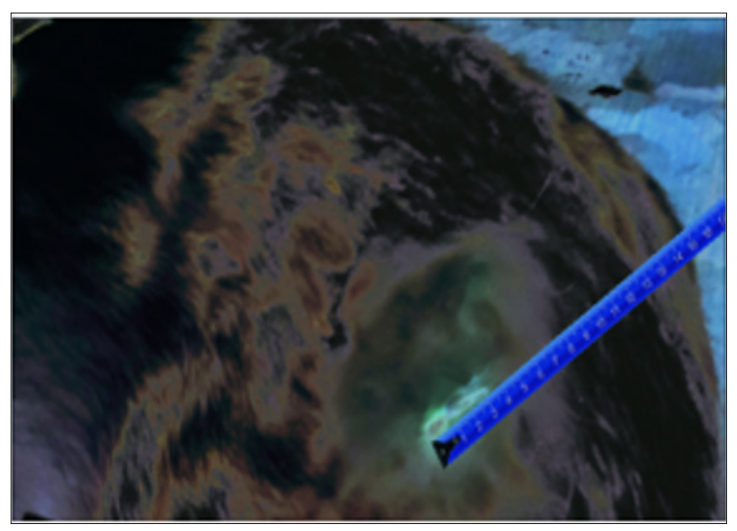

Figure 3: Wound at day 7.

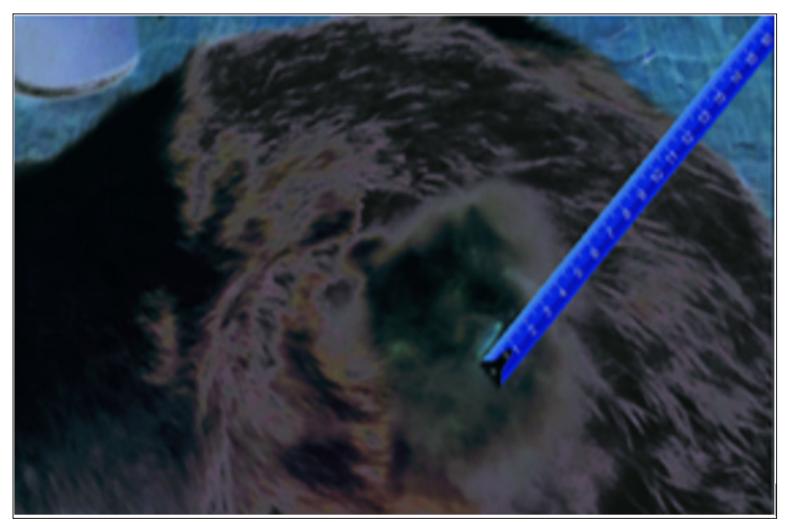

Figure 4: Wound at day 14.

\section{Discussion}

Inflammation is a physiological response from the body against the pathogens and macrophages play a big role through multiple cytokines production like TNF- $\alpha$ (tumor necrosis factor- $\alpha$ ), IL$1 \alpha$ (interleukin $1-\alpha$ ), IL-1 $\beta$ (interleukin 1- $\beta$ ), IL-6 (interleukin 6) and NO (nitric oxide) [10]. Any agent that interferes with these mediators will reduce the inflammation. Clay was studied by many workers and found promising results Keith D. Morrison (2016) reported antibacterial effects of the clay against the $E$. coli and MRS (methicillin resistant staphylococcus) and attributed this activity of clay with its soluble reduced metals and expandable clay minerals that absorb cations, providing a capacity for extended metal release and production of toxic hydroxyl radicals. $\mathrm{Fe}_{2}{ }^{+}$and $\mathrm{Al}_{3}{ }^{+}$ that synergistically attack multiple cellular systems in pathogens [11]. Lynda B. Williams (2011) also found antibacterial effects of clay against E. coli [12]. Complete eradication by clay has also been reported for Staphylococcus aureus, methicillin resistant S. aureus (MRSA), Escherichia coli, Pseudomonas aeruginosa and Salmonella typhi in published literature [13]. Another type of clay from British Columbia, Canada, Kisameet glacial clay has shown strong antibacterial action against Enterococcus faecium, Klebsiella, Staph. aureus, Pseudomonas aeruginosa and Acinetobacter baumannii, and anti-fungal activity against Cryptococcus neoformans and Candida albicans [14]. Shehab A Lafi (2011) also reported the Egyptian clay to be effective against pseudomonas aeruginosa and Staph. Aureus [15].

Current experiments demonstrated bentonite to help in the healing process from reduction of inflammatory reaction to increased fibroblast migration. Wound healing was seen over two weeks with maximum collagen deposition on histological examinations. The exact mechanism for this aspect of bentonite is yet to be known but we observed intense reaction (inflammatory) was converted into moderate one after 1 week that further improved by bentonite to a very mild category at two weeks. Emami (2006) results also showed reduced inflammatory response to a significant level on treatment with Bentonite [16]. Angiogenesis, an important step in wound healing that enhances the circulation of blood to the injured area to facilitate oxygen and nutrients supply was also improved by Bentonite from 3rd day and onward. We could not evaluate the possible mechanisms involved in these antiinflammatory and wound healing properties of bentonite due to our financial limitations that remained the weakness of our study. Bentonite may have some inhibitory effects on arachidonic acid break down pathways and cytokine involved in the inflammatory process that is what we recommend and plan to explore in the future.

\section{Conclusion}

Bentonite possesses strong anti-inflammatory and wound healing properties.

\section{References}

1. Erica D Bruce, Christie M Sayes (2016) Toxicological Outcomes and Pharmacological Needs in Chronic Wound Healing. EC Pharmacology and Toxicology 1(1): 15-32.

2. Gainza G, Villullas S, Pedraz JL, Hernandez RM, Igartua M (2015) Advances in drug delivery systems (DDSs) to release growth factors for wound healing and skin regeneration. Nanomedicine: Nanotechnology, Biology and Medicine 11(6): 1551-1573.

3. Mathieu P Rodero, Kiarash Khosro Tehrani (2010) Skin wound healing modulation by macrophages. Int J Clin Exp Pathol 3(7): 643-653.

4. Johnstone CC, Farley A, Hendry C (2005) The physiological basics of wound healing. Nursing Standard. 19(43): 59-65.

5. Sansom LN (2012) Pharmaceutical Society of Australia Australian pharmaceutical formulary and handbook: The everyday guide to 
pharmacy practice. In Sansom LN (Eds.) (22 nd edn) Deakin West, ACT, Australia, UK

6. Suajatmiko Gentur, Vika Tania (2012) Key points in Wound Contractures. Jurnal Plastik Rekonstruksi 1(6): 439-542.

7. Hao Liu, Bing Xie, Yue lin Qin (2017) Effect of Bentonite on the Pelleting Properties of Iron Concentrate. Journal of chemistry p. 1-6.

8. Muhammad Nafees, Amir Waseem, Abdur Rehman Khan (2013) Comparative Study of Laterite and Bentonite Based Organoclays: Implications of Hydrophobic Compounds Remediation from Aqueous Solutions. The Scientific World Journal. Article ID 681769.

9. Lynda B Williams, Shelley E Haydel (2010) Evaluation of the medicinal use of clay minerals as antibacterial agents. Int Geol Rev 52(7-8): 745770.

10. Wan Kyu Ko, Soo Hong Lee, Sung Jun Kim, Min Jae Jo, Hemant Kumar, et al. (2017) Anti-inflammatory effects of ursodeoxycholic acid by lipopolysaccharide-stimulated inflammatory responses in RAW 264.7macrophages. PLoS ONE 12(6): e0180673.

\section{ISSN: 2574-1241}

DOI: 10.26717/BJSTR.2018.10.001921

Qamar Zaman Phull. Biomed J Sci \& Tech Res

(C) (i) This work is licensed under Creative

Submission Link: https://biomedres.us/submit-manuscript.php
11. Keith D Morrison, Rajeev Misra, Lynda B Williams (2016) Unearthing the Antibacterial Mechanism of Medicinal Clay: A Geochemical Approach to Combating Antibiotic Resistance. Scientific Reports 6: 19043.

12. Lynda B Williams, David W Metge, Dennis D Eberl, Ronald W Harvey, Amanda G Turner (2011) What Makes a Natural Clay Antibacterial? Environ. Sci Technol 45: 3768-3773.

13. Cunningham TB, Koehl J L, Summers JS, Haydel SE (2010) pH-dependent metal ion toxicity influences of the antibacterial activity of two natural mineral mixtures. PLoS-ONE 5: e9456.

14. Sarah L Svensson, Shekooh Behroozian, Wanjing Xu, Michael G Surette, Loretta Li (2017) Kisameet Glacial Clay: An Unexpected Source of Bacterial Diversity 8(3): e00590-17.

15. Shehab A Lafi, Mohammed R Al Dulaimy (2011) Antibacterial Effect of some Mineral Clays In Vitro. Egypt Acad J biolog Sci 3(1): 75-81.

16. Emami Razvi SH, Esmaeilli SK, S Amanpour, S Rabbani, AM Alizadeh, et al. (2006) Effect of bentonite on skin wound healing: Experimental study in the rat model. Acta medica Iranica 44(4): 235-240.

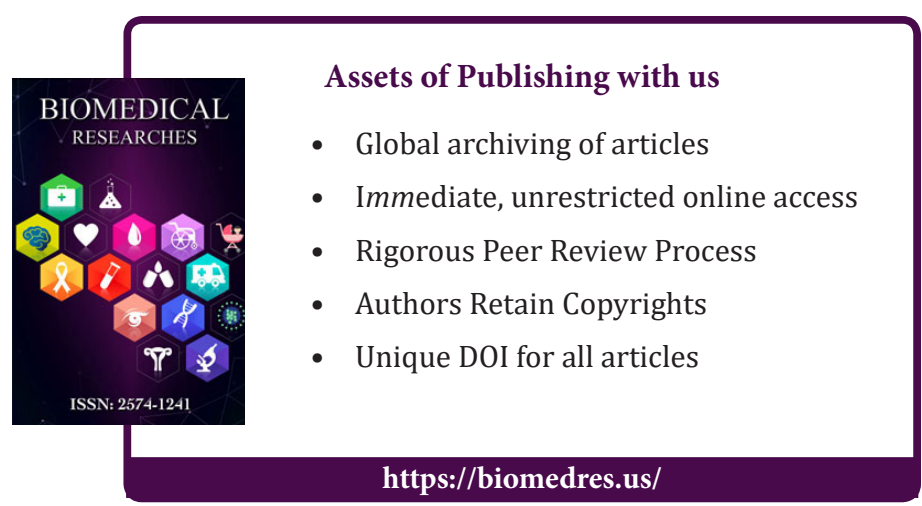

